\title{
SCIENTIFIC REPORTS

\section{Characterization of variations within the rumen metaproteome of Holstein dairy cattle relative to morning feed offering}

\begin{abstract}
Mallory C. Honan \& Sabrina L. Greenwood $\mathbb{D}^{*}$
Few studies have utilized proteomic techniques to progress our knowledge of protein-mediated pathways within the rumen microbial community, and no previous research has used these techniques to investigate the patterns or variations of these proteins within this community. It was hypothesized that there would be fluctuations of rumen microbial protein abundances due to feed intake-mediated nutrient availability and that these could be identified using non gel-based proteomic techniques. This study investigated the fluctuations of bovine rumen metaproteome utilizing three mid to late-lactation Holsteins. Rumen fluid was collected at three timepoints on three days relative to their first morning feed offering ( $0 \mathrm{~h}, 4 \mathrm{~h}$, and $6 \mathrm{~h}$ ). Samples were pooled within timepoint within cow across day, analyzed using LC-MS/MS techniques, and analyzed for variations across hour of sampling using PROC MIXED of SAS with orthogonal contrasts to determine linear and quadratic effects. A total of 658 proteins were characterized across 19 microbial species, with 68 proteins identified from a variety of 15 species affected by time of collection. Translation-related proteins such as $50 \mathrm{~S}$ and $30 \mathrm{~S}$ ribosomal protein subunit variants and elongation factors were positively correlated with hour of sampling. Results suggest that as nutrients become more readily available, microbes shift from conversion-focused biosynthetic routes to more encompassing DNA-driven pathways.
\end{abstract}

The pregastric rumen is the dominant site of microbial colonization and microbe-mediated fermentation within the ruminant digestive tract, and functionality of this chamber is a key factor that dictates the animal's efficiency of nutrient utilization and production ${ }^{1-4}$. Feed and production efficiency, ruminant animal health, and environmental emissions are all affected by rumen ecology, hence there is growing interest within the ruminant livestock sector to understand the in situ or vivo functionality within and among rumen microbes. Current knowledge of the rumen microbiome is cross-disciplinary and rapidly expanding, with novel research emerging that is focused on diversity analysis and community structures of the microbiota ${ }^{5-8}$, as well as metabolic pathway analysis and metatranscriptomics ${ }^{9-12}$.

Despite advances in our understanding, there is still a gap in knowledge regarding the undercurrents and interplay of microbe-specific metabolic pathways because of their dynamicity, adaptability, and complexity. Utilizing a variety of approaches to characterize the rumen in terms of microbial ecology and pathway dynamics appears to be necessary. For instance, microbial diversity analysis has revealed that basal diet and diurnal rumen pH patterns can be somewhat independent of bacterial community profile ${ }^{13}$, while more recently, Söllinger et al. ${ }^{14}$ paired metabolomics with quantitative metatranscriptomics to assess the diurnal fluctuations of individual rumen microorganisms and also reported a dissociation between the functional microbial transcripts and microbiome pathway products such as methane. Layered within these challenges, the central dogma of translation appears to be disjointed, with microbial RNA not reflective of protein abundances within the rumen, possibly due to post-translational modifications along with other adaptations ${ }^{14-16}$. In addition, issues such as a limitation in analytic capabilities to discern in vivo complexities and variations due to external drivers such as endogenous and management influences, have slowed progress and the application of knowledge to commercial systems.

Proteomic techniques are now integrated in livestock research, with published applications in milk ${ }^{17-19}$, urine $^{20-22}$, plasma ${ }^{23,24}$, and reproductive fluid ${ }^{25,26}$. Proteomic characterization of the rumen metaproteome 
includes unique challenges due to the multitude of residing organisms, but undoubtedly would yield valuable data bearing in mind the reliance of animal production on protein-mediated pathways and microbial protein production. Only two known previous works have been published that apply proteomic techniques to investigate the protein profile of the rumen, both utilizing gel techniques which may limit the number of proteins that can be identified $^{15,27}$. Using these techniques, Snelling and Wallace ${ }^{27}$ were able to identify 50 unique proteins in rumen fluid samples collected from beef cattle and lambs; however, protein identification in rumen fluid samples collected from grazing dairy cattle was not achieved due to obstruction of protein bands on the gels by plant-based humic compounds. More recently, Hart et al. ${ }^{15}$ used gel-based techniques to examine the rumen metaproteome, and included successful techniques to partially separate interfering contaminants, including humic acid, from the protein extract. Both publications provided valuable solutions to methodological challenges and a first glimpse of microbe-specific proteins in the rumen. Combining these protein isolation techniques with newer isobaric labeling methods was hypothesized to be a feasible approach to broaden the scope of rumen metaproteome characterization. It was further hypothesized that there would be fluctuations in rumen microbial protein abundances due to feed intake-mediated nutrient availability in lactating dairy cattle. The objectives of this experiment were to use non gel-based fractionation methods and isobaric labeling techniques to further the characterization of the rumen metaproteome within Holstein dairy cattle and identify whether variations in these profiles relative to first morning feed offering could be elucidated using this approach.

\section{Results}

Metaproteomic analysis using the outlined protocol resulted in identification of 698 proteins across 19 microbial species including multiple strains (see Supplementary Table S1 for list of proteins identified within species and Supplementary Table S2 for data files). Using Proteome Discoverer 2.2, the proteins from the following microbial species and their strains were identified: Butyrivibrio hungatei MB2003, Butyrivibrio hungatei XBD2006, Butyrivibrio hungatei DSM 14810, [Eubacterium] cellulosolvens 6, Eubacterium ruminantium, Fibrobacter succinogenes (strain ATCC 19169/S85), Lactobacillus ruminis ATCC 27782/RF3, Megasphaera elsdenii DSM 20460, Methanosarcina barkeri 3, Oxalobacter formigenes HOxBLS, Ruminococcus albus SY3, Prevotella aff. ruminicola Tc2-24, Prevotella bryantii FB3001, Prevotella bryantii KHPX14, Prevotella bryantii TC1-1, Prevotella bryantii B14, Prevotella ruminicola (Bacteroides ruminicola) AR32, Prevotella ruminicola (Bacteroides ruminicola) ATCC 19189, Prevotella ruminicola (Bacteroides ruminicola) BPI-162, Prevotella ruminicola (Bacteroides ruminicola) BPI-34, Prevotella ruminicola (Bacteroides ruminicola) D31d, Prevotella ruminicola (Bacteroides ruminicola) KHT3, Prevotella ruminicola ATCC 19189/JCM 8958/23 and ATCC 19189/JCM 8958/23, Pseudobacteroides cellulosolvens ATCC 35603/DSM 2933, Pseudobutyrivibrio ruminis ACV-9, Pseudobutyrivibrio ruminis JK10, Pseudobutyrivibrio ruminis JK626, Pseudobutyrivibrio ruminis DSM 9787, Ruminococcus bromii 5AMG, Ruminococcus bromii AF15-36, Ruminococcus bromii AF21-10LB, Ruminococcus bromii AF25-7LB, Ruminococcus bromii AM32-13AC, Ruminococcus bromii AM46-2BH, Ruminococcus bromii ATCC 27255, Ruminococcus bromii CF01-14, Ruminococcus bromii L2-36, Ruminococcus bromii TM09-18AC, Ruminococcus bromii TM09-5AC, Ruminococcus bromii TM10-21, Ruminococcus bromii YE282, Ruminococcus bromii L2-63, Ruminococcus flavefaciens 007c, Treponema bryantii, Treponema saccharophilum DSM 2985, and Wolinella succinogenes ATCC 29543/DSM 1740/LMG 7466/NCTC 11488/FDC 602 W. Of the 698 proteins identified across all searched species, 658 proteins were labeled and present in all samples, and these were quantified for downstream statistical analysis and bioinformatics (Supplementary Table S2). Results were grouped and interpreted based on abundance pattern shifts relative to morning feeding with LOW0 representing proteins that demonstrated an increase in abundance either quadratically or linearly relative to initial sampling $(0 \mathrm{~h})$ and HIGH0 representing proteins that began with a higher abundance at $0 \mathrm{~h}$ and had either a linear or quadratic decrease in the latter sampling points at $4 \mathrm{~h}$ and $6 \mathrm{~h}$.

Of the quantified proteins, there were 68 proteins across 15 microbial species that were affected by time of sampling, including $88.2 \%$ that responded linearly, and $30.9 \%$ being affected by a quadratic pattern of change.

Microbial proteins with an increase in abundance from $\mathbf{0 ~} \mathrm{h}$ to $\mathbf{4} \mathrm{h}$. There were 10 microbial species with proteins represented in this group (LOW0): E. cellulosolvens, B. hungatei, P. aff. Ruminicola, P. bryantii, $P$. ruminicola, $P$. ruminis, $R$. albus, $R$. flavefaciens, and T. saccharophilum. Of the proteins that were affected by time of sampling, $45.6 \%$ had lower abundances at $0 \mathrm{~h}$ compared to $4 \mathrm{~h}$. As represented in Table 1,16 of the LOW0 proteins were different variants of the 50 s ribosomal protein (L14, R. flavefaciens; L33, L7/12, E. cellulosolvens; L6, $R$. albus; L3, L14, L16, L21, L31, P. aff. ruminicola; L1, L16, P. ruminicola; L21, L22, P. ruminis; L4, L5, R. bromii; L11, T. saccharophilum), while shifts in abundance of individual $30 \mathrm{~s}$ ribosomal proteins (S11, and S5) from E. cellulosolvens, B. hungatei, P. aff. ruminicola, and P. ruminicola, totaled 6 of the proteins in LOW0 based on their abundance patterns. Elongation factor proteins of E. cellulosolvens (elongation factor Tu) and P. ruminis, and R. bromii (elongation factor $\mathrm{G}$ ) were lower in abundance at $0 \mathrm{~h}$ compared to $4 \mathrm{~h}$. Other proteins that were lower in abundance at $0 \mathrm{~h}$ compared to $4 \mathrm{~h}$ that were unique to a specific species were those from $P$. ruminicola, including starch phosphorylase, alpha-amylase, and carboxypeptidase regulatory-like domain-containing protein.

Microbial proteins with a decrease in abundance from $\mathbf{0 ~} \mathrm{h}$ to $\mathbf{4} \mathrm{h}$. There were 12 microbial species represented in the HIGH0 group: E. cellulosolvens, B. hungatei, E. ruminantium, F. succinogenes, M. elsdenii, $M$. barkeri, P. ruminicola, P. ruminis, $R$. albus, $R$. flavefaciens, T. saccharophilum, ${ }^{\mathrm{T}}$ and $W$. succinogenes. The functional groupings of proteins that had higher abundances at $0 \mathrm{~h}$ compared to $4 \mathrm{~h}(54.4 \%$ of proteins affected by time of sampling) are listed in Table 1 . There was a single 50 s ribosomal protein (from E. ruminantium) that exhibited a decrease in abundance from $0 \mathrm{~h}$ to $4 \mathrm{~h}$. 


\begin{tabular}{|c|c|c|c|c|c|c|c|c|c|}
\hline Protein & Description & Species & oh & $4 \mathrm{~h}$ & $6 \mathrm{~h}$ & SE & $\begin{array}{l}\text { Pvalue } \\
\text { linear }\end{array}$ & $\begin{array}{l}\text { P value } \\
\text { quadratic }\end{array}$ & Group \\
\hline A0A1D9P0Y8 & Sugar $\mathrm{ABC}$ transporter substrate-binding protein & Butyrivibrio hungatei & 105.23 & 97.40 & 97.30 & 0.50 & $<0.0001$ & 0.007 & HIGH0 \\
\hline C9RNK1 & DNA-binding protein $\mathrm{HU}$ & Fibrobacter succinogenes & 121.10 & 89.30 & 89.53 & 3.70 & 0.001 & 0.059 & HIGH0 \\
\hline I5ATH2 & $50 \mathrm{~S}$ ribosomal protein $\mathrm{L} 7 / \mathrm{L} 12$ & [Eubacterium] cellulosolvens & 91.40 & 104.93 & 103.67 & 1.47 & 0.001 & 0.027 & LOW0 \\
\hline A0A1D9P1Q9 & FeS cluster assembly scaffold protein NifU & Butyrivibrio hungatei & 102.90 & 98.13 & 98.93 & 0.50 & 0.001 & 0.015 & HIGH0 \\
\hline A0A1I0LZ55 & 50S ribosomal protein L21 & Prevotella aff. ruminicola & 93.60 & 102.33 & 104.10 & 1.23 & 0.001 & 0.302 & LOW0 \\
\hline A0A1T4M509 & 50S ribosomal protein L27 & Eubacterium ruminantium & 106.37 & 100.03 & 93.57 & 1.39 & 0.001 & 0.252 & HIGH0 \\
\hline A0A2G3DV35 & Phosphoenolpyruvate carboxykinase (ATP) & Pseudobutyrivibrio ruminis & 109.40 & 96.03 & 94.53 & 1.77 & 0.001 & 0.169 & HIGH0 \\
\hline D5EY74 & Cysteine synthase & Prevotella ruminicola & 106.40 & 98.30 & 95.33 & 1.30 & 0.001 & 0.672 & HIGH0 \\
\hline A0A1M6WB45 & Starch phosphorylase & Prevotella ruminicola & 97.47 & 102.03 & 100.47 & 0.42 & 0.001 & 0.003 & LOW0 \\
\hline A0A1H9AWB6 & $\begin{array}{l}\text { TonB-linked outer membrane protein, SusC/RagA } \\
\text { family }\end{array}$ & Prevotella bryantii & 94.07 & 107.23 & 98.67 & 0.84 & 0.001 & $<0.0001$ & LOW0 \\
\hline A0A1H7IVN8 & Phosphoenolpyruvate carboxykinase (ATP) & Pseudobutyrivibrio ruminis & 106.70 & 97.57 & 95.73 & 1.59 & 0.002 & 0.395 & HIGH0 \\
\hline C9RP04 & Fructose-bisphosphate aldolase, class II & Fibrobacter succinogenes & 102.90 & 98.70 & 98.43 & 0.67 & 0.002 & 0.193 & HIGH0 \\
\hline W7UDV4 & Pyruvate, phosphate dikinase & Ruminococcus flavefaciens & 104.93 & 95.20 & 99.90 & 0.98 & 0.003 & 0.002 & HIGH0 \\
\hline A0A1G5ID80 & 50S ribosomal protein L5 & Ruminococcus bromii & 96.63 & 99.30 & 104.07 & 1.08 & 0.004 & 0.140 & LOW0 \\
\hline W7UL50 & Nitrogen-fixing protein NifU & Ruminococcus flavefaciens & 114.63 & 89.93 & 95.40 & 3.60 & 0.005 & 0.038 & HIGH0 \\
\hline A0A1IOPQF4 & 50S ribosomal protein L31 type B & Prevotella aff. ruminicola & 93.50 & 102.10 & 104.40 & 1.89 & 0.005 & 0.592 & LOW0 \\
\hline W7UUA7 & Cysteine synthase & Ruminococcus flavefaciens & 109.07 & 95.70 & 95.23 & 2.49 & 0.005 & 0.230 & HIGH0 \\
\hline H7ENF3 & 50S ribosomal protein L11 & Treponema saccharophilum & 94.50 & 101.23 & 104.23 & 1.68 & 0.006 & 0.911 & LOW0 \\
\hline A0A1D9P2Q2 & DNA-binding protein & Butyrivibrio hungatei & 106.17 & 97.70 & 96.03 & 1.84 & 0.006 & 0.483 & HIGH0 \\
\hline A0A1H7G1G5 & GGGtGRT protein & Pseudobutyrivibrio ruminis & 106.00 & 94.90 & 99.07 & 1.58 & 0.009 & 0.017 & HIGH0 \\
\hline I5AT53 & Elongation factor $\mathrm{Tu}$ & [Eubacterium] cellulosolvens & 95.53 & 100.60 & 103.90 & 1.60 & 0.010 & 0.806 & LOW0 \\
\hline I5ATH8 & 50S ribosomal protein L33 & [Eubacterium] cellulosolvens & 86.63 & 108.63 & 104.77 & 3.93 & 0.010 & 0.090 & LOW0 \\
\hline A0A1T4L946 & GGGtGRT protein & Eubacterium ruminantium & 104.27 & 97.60 & 98.13 & 1.33 & 0.011 & 0.172 & HIGH0 \\
\hline I5AUJ3 & Phosphomannomutase & [Eubacterium] cellulosolvens & 104.60 & 98.10 & 97.30 & 1.53 & 0.011 & 0.424 & HIGH0 \\
\hline A0A1H3ZTM3 & DUF4301 domain-containing protein & Prevotella ruminicola & 106.00 & 96.90 & 97.10 & 1.95 & 0.012 & 0.241 & HIGH0 \\
\hline C9RPJ7 & Phosphoenolpyruvate carboxykinase [GTP] & Fibrobacter succinogenes & 102.93 & 99.47 & 97.63 & 1.08 & 0.013 & 0.962 & HIGH0 \\
\hline A0A1H7IZW1 & O-acetylhomoserine (Thiol)-lyase & Pseudobutyrivibrio ruminis & 108.70 & 93.90 & 97.37 & 2.66 & 0.013 & 0.072 & HIGH0 \\
\hline A0A1H4EPE5 & Branched-chain amino acid aminotransferase & Prevotella ruminicola & 104.43 & 97.97 & 97.63 & 1.57 & 0.016 & 0.362 & HIGH0 \\
\hline H7ELT1 & Cysteine synthase & Treponema saccharophilum & 106.77 & 97.00 & 96.27 & 2.46 & 0.018 & 0.402 & HIGH0 \\
\hline G0VRR0 & Band_7_1 domain-containing protein & Megasphaera elsdenii & 103.57 & 97.57 & 98.87 & 1.21 & 0.019 & 0.106 & HIGH0 \\
\hline A0A011UEZ1 & Pyruvate-flavodoxin oxidoreductase & Ruminococcus albus & 102.40 & 100.10 & 97.50 & 1.08 & 0.020 & 0.500 & HIGH0 \\
\hline A0A2N0UJ77 & Elongation factor $\mathrm{G}$ & Ruminococcus bromii & 96.43 & 99.77 & 103.80 & 1.64 & 0.021 & 0.469 & LOW0 \\
\hline A0A1I0P7E5 & $50 \mathrm{~S}$ ribosomal protein $\mathrm{L} 3$ & Prevotella aff. ruminicola & 93.23 & 104.20 & 102.53 & 2.41 & 0.022 & 0.164 & LOW0 \\
\hline W7UV65 & 50S ribosomal protein L14 & Ruminococcus flavefaciens & 95.73 & 100.47 & 103.83 & 1.90 & 0.024 & 0.788 & LOW0 \\
\hline A0A1I0P5X6 & $30 \mathrm{~S}$ ribosomal protein $\mathrm{S} 11$ & Prevotella aff. ruminicola & 90.57 & 107.53 & 101.90 & 3.29 & 0.027 & 0.062 & LOW0 \\
\hline A0A1M6U920 & $30 \mathrm{~S}$ ribosomal protein $\mathrm{S} 5$ & Prevotella ruminicola & 93.17 & 103.60 & 103.20 & 2.68 & 0.027 & 0.305 & LOW0 \\
\hline A0A1D9P3D5 & 30S ribosomal protein S5 & Butyrivibrio hungatei & 91.67 & 100.60 & 107.73 & 3.90 & 0.027 & 0.727 & LOW0 \\
\hline A0A1H3YTN0 & Phosphate acetyltransferase & Prevotella ruminicola & 103.47 & 98.00 & 98.53 & 1.35 & 0.028 & 0.242 & HIGH0 \\
\hline A0A1T4JZ88 & Acyl-CoA dehydrogenase & Eubacterium ruminantium & 104.67 & 98.50 & 96.87 & 2.00 & 0.028 & 0.712 & HIGH0 \\
\hline A0A1I0P683 & $30 \mathrm{~S}$ ribosomal protein S5 & Prevotella aff. ruminicola & 95.83 & 103.87 & 100.27 & 1.39 & 0.029 & 0.027 & LOW0 \\
\hline A0A1D9P124 & Glycogen synthase & Butyrivibrio hungatei & 104.80 & 97.03 & 98.20 & 1.88 & 0.031 & 0.200 & HIGH0 \\
\hline A0A1H5TKQ7 & $\begin{array}{l}\text { TonB-linked outer membrane protein, SusC/RagA } \\
\text { family }\end{array}$ & Prevotella ruminicola & 97.30 & 102.37 & 100.37 & 0.96 & 0.032 & 0.045 & LOW0 \\
\hline A0A0E3SKP3 & $60 \mathrm{kDa}$ chaperonin & Methanosarcina barkeri & 102.87 & 98.53 & 98.60 & 1.19 & 0.032 & 0.354 & HIGH0 \\
\hline A0A1H6LAW0 & $\begin{array}{l}\text { Carboxypeptidase regulatory-like domain- } \\
\text { containing protein }\end{array}$ & Prevotella ruminicola & 95.70 & 103.03 & 101.27 & 1.65 & 0.033 & 0.129 & LOW0 \\
\hline A0A011V0N9 & Triosephosphate isomerase & Ruminococcus albus SY3 & 108.47 & 91.30 & 100.20 & 2.87 & 0.036 & 0.017 & HIGH0 \\
\hline A0A1H5WW23 & $30 \mathrm{~S}$ ribosomal protein $\mathrm{S} 7$ & Prevotella ruminicola & 96.07 & 105.00 & 98.93 & 1.17 & 0.036 & 0.003 & LOW0 \\
\hline A0A011V181 & $50 \mathrm{~S}$ ribosomal protein $\mathrm{L} 6$ & Ruminococcus albus & 91.87 & 102.53 & 105.63 & 3.81 & 0.037 & 0.765 & LOW0 \\
\hline A0A1I0P6K5 & 50S ribosomal protein L14 & Prevotella aff. ruminicola & 94.23 & 103.83 & 101.97 & 2.35 & 0.038 & 0.181 & LOW0 \\
\hline A0A1H5VAJ1 & Fumarate hydratase class I & Prevotella ruminicola & 104.63 & 98.57 & 96.80 & 2.18 & 0.038 & 0.767 & HIGH0 \\
\hline A0A1T4MD15 & Glyceraldehyde-3-phosphate dehydrogenase & Eubacterium ruminantium & 103.57 & 98.23 & 98.20 & 1.57 & 0.039 & 0.404 & HIGH0 \\
\hline I5AVX2 & $30 \mathrm{~S}$ ribosomal protein $\mathrm{S} 11$ & [Eubacterium] cellulosolvens & 97.80 & 101.33 & 100.90 & 0.95 & 0.041 & 0.260 & LOW0 \\
\hline A0A1H5SU14 & Phosphoenolpyruvate carboxykinase (ATP) & Prevotella ruminicola & 101.97 & 99.70 & 98.33 & 1.00 & 0.041 & 0.905 & HIGH0 \\
\hline A0A1H7LBE7 & $\begin{array}{l}\text { Benzoyl-CoA reductase/2-hydroxyglutaryl-CoA } \\
\text { dehydratase subunit, } \mathrm{BcrC} / \mathrm{BadD} / \mathrm{HgdB}\end{array}$ & Pseudobutyrivibrio ruminis & 102.83 & 100.03 & 97.13 & 1.53 & 0.042 & 0.619 & HIGH0 \\
\hline
\end{tabular}




\begin{tabular}{|c|c|c|c|c|c|c|c|c|c|}
\hline Protein & Description & Species & $\mathbf{0 h}$ & $4 \mathrm{~h}$ & $6 \mathrm{~h}$ & SE & $\begin{array}{l}\text { P value } \\
\text { linear }\end{array}$ & $\begin{array}{l}\text { P value } \\
\text { quadratic }\end{array}$ & Group \\
\hline A0A1D9P3R0 & 3-hydroxyacyl-CoA dehydrogenase & Butyrivibrio hungatei & 108.47 & 95.03 & 96.50 & 3.67 & 0.042 & 0.278 & HIGH0 \\
\hline D5EZ18 & Uncharacterized protein & Prevotella ruminicola & 96.00 & 101.27 & 102.77 & 1.94 & 0.042 & 0.765 & LOW0 \\
\hline A0A1H7FPT3 & 50S ribosomal protein L21 & Pseudobutyrivibrio ruminis & 93.77 & 104.53 & 101.63 & 2.54 & 0.042 & 0.131 & LOW0 \\
\hline A0A1H7FUZ2 & Elongation factor $\mathrm{G}$ & Pseudobutyrivibrio ruminis & 97.23 & 101.17 & 101.63 & 1.30 & 0.043 & 0.560 & LOW0 \\
\hline A0A011V4S8 & Glyceraldehyde-3-phosphate dehydrogenase & Ruminococcus albus SY3 & 105.93 & 95.33 & 98.77 & 2.38 & 0.044 & 0.098 & HIGH0 \\
\hline A0A1G5IE48 & 50 S ribosomal protein $\mathrm{L} 4$ & Ruminococcus bromii & 95.43 & 100.93 & 103.63 & 2.32 & 0.044 & 0.991 & LOW0 \\
\hline A0A1H7KRN7 & 50S ribosomal protein L22 & Pseudobutyrivibrio ruminis & 90.73 & 106.67 & 102.60 & 3.89 & 0.046 & 0.149 & LOW0 \\
\hline W7UV77 & Twitching motility protein pilT & Ruminococcus flavefaciens & 108.67 & 89.77 & 101.57 & 3.17 & 0.061 & 0.012 & HIGH0 \\
\hline A0A1H4EAK7 & 50 S ribosomal protein $\mathrm{L} 1$ & Prevotella ruminicola & 94.87 & 105.67 & 99.47 & 2.34 & 0.103 & 0.038 & LOW0 \\
\hline D5EX68 & Acyl carrier protein & Prevotella ruminicola & 111.80 & 86.23 & 101.93 & 5.29 & 0.106 & 0.028 & HIGH0 \\
\hline Q7MSE9 & Pilin biogenesis & Wolinella succinogenes & 109.00 & 89.73 & 101.30 & 4.29 & 0.122 & 0.038 & HIGH0 \\
\hline A0A1I0P6T5 & 50S ribosomal protein L16 & Prevotella aff. ruminicola & 96.30 & 104.33 & 99.37 & 1.95 & 0.160 & 0.049 & LOW0 \\
\hline A0A1H4CD71 & Alpha-amylase & Prevotella ruminicola & 98.70 & 102.57 & 98.77 & 0.70 & 0.398 & 0.005 & LOW0 \\
\hline D5EUS6 & 50S ribosomal protein L16 & Prevotella ruminicola & 97.73 & 110.00 & 92.30 & 4.06 & 0.731 & 0.020 & LOW0 \\
\hline G0VPW5 & $60 \mathrm{kDa}$ chaperonin & Megasphaera elsdenii & 101.73 & 95.27 & 103.00 & 1.91 & 0.913 & 0.022 & HIGH0 \\
\hline
\end{tabular}

Table 1. Scaled abundance values of the 68 proteins within strained rumen grab samples collected from Holstein dairy cows that were affected by time of sampling relative to morning feeding $(0 \mathrm{~h}, 4 \mathrm{~h}$, or $6 \mathrm{~h}$ after feeding). Proteins were grouped by whether they increased (LOW0) or decreased (HIGH0) in abundance either linearly or quadratically relative to $0 \mathrm{~h}$ sampling.

\section{Discussion}

Understanding microbial metabolism is a crucial step in the development of strategies to support and sustain maximal nutrient use efficiency in the rumen. Inclusion of proteomic techniques to articulate the underlying shifts in the rumen metaproteome is in its infancy, but gel-based protein fractionation from samples collected in static points of time highlight the breadth of protein identifications that can be achieved ${ }^{15,27}$. Using a combination of rumen-specific fractionation protocols with isobaric labeling techniques, the research reported herein is the first to outline the potential dynamic range of the rumen microbial metaproteome relative to first morning feeding. For this research, 47 composite database searches were completed, encompassing 19 microbial species and numerous strains. While this represents only a small fraction of the rumen microbiota, and further work must be done to ensure inclusive and accurate proportional representation of the rumen microbiota, this research encompasses the largest rumen metaproteomic search to date. Snelling and Wallace ${ }^{27}$ were unable to characterize the metaproteome of grazing dairy cattle due to impeding compounds on gels, however, they were able to distinguish 50 unique proteins derived from other ruminants such as lambs and beef cattle. Hart et al. ${ }^{15}$ highlighted the 25 most common protein families found within each individual cow and discussed phyla dominance but did not delineate proteomes of specific microbes.

In the present study, there were 43 variants of ribosomal proteins characterized within this research $(1630 \mathrm{~s}$ and $2750 \mathrm{~s}$ ) across 16 microbial species and is the most represented protein in this study. While some of these identified proteins may be redundant due to overlapping peptide sequences, approximately $20 \%$ of bacterial dry weight is made up of ribosomal proteins so it is not unexpected to see that these proteins are the majority of identified proteins ${ }^{28}$. These ribosomal proteins are subunits within a larger bacterial ribosome that serves in mRNA translation to protein, and each subunit serves a specific function. The smaller $30 \mathrm{~s}$ subunit decodes the mRNA strand while the larger $50 \mathrm{~s}$ subunit assists in peptide bonding of the specified amino acids. Another protein involved heavily in the central dogma, elongation factor $\mathrm{Tu}$, was also a widely represented protein being characterized within 13 microbial species. This protein contributes to the continuous process of sequentially adding amino acids to a peptide chain. Overall, nearly all LOW0 proteins are translation-related. Ribosomal proteins $(50 \mathrm{~s}$ and $30 \mathrm{~s})$ and their associated variants were the most commonly affected proteins across sampling time with $53.5 \%$ of identified ribosomal proteins being affected by time of sampling, and $95.7 \%$ of the affected ribosomal proteins being represented in LOW0. Elongation factors (G, R. flavefaciens; Tu, P. ruminis and R. bromii) showed an increase in abundance relative to $0 \mathrm{~h}$ which also placed them in the LOW0 group.

To interpret the results, we broadly partitioned the rumen metaproteome into two conceptual categories, the first category being the above discussed general pathways of transcription and translation. The second category includes proteins with more specific roles in metabolic pathways. While it can be difficult to draw conclusions regarding the substrate or environmental drivers causing an increase in proteins related to translational processing beyond simply surmising that protein synthesis is likely increasing, there were many proteins identified in the current study that are key players in many specific metabolic pathways, highlighting possible shifts in more specific rumen functionality. In contrast to proteins grouped in LOW0, in HIGH0 there was largely a lack of representation of $30 \mathrm{~s} / 50 \mathrm{~s}$ ribosomal proteins, elongation factors, and other translation-related proteins. Instead, there were shifts in proteins with more targeted functions, such as fumarate hydrolase, phosphoenol pyruvate carboxykinase, cysteine synthase, nitrogen-fixing protein NifU, GGGtGRT protein, pyruvate, phosphate dikinase, and glyceraldehyde-3-phosphate dehydrogenase (GAPDH). These results highlight the concept that rumen microbiota are independently reactive to their environment but yet are in synchrony with each other. Investigation of only the substrates or products within the rumen would not have likely yielded a comprehensive 
understanding of the individual microbial activities including the extent of synchronicity or similarity in protein profile across the different species within the rumen.

A consideration from the results is that the identified protein shifts illustrate that feeding protocol- and bunk management- induced fasting periods may quickly limit potential productivity of microbes. It is important to note that only $10.3 \%$ of analyzed proteins were affected by time of sampling, and could be due to the fact that cows were not fasted or subject to a more significant dietary perturbance or limitation beyond typical daily feeding schedule. Regardless, these results provide insight into the pathways and microbes more readily impacted by substrate-mediated suppression of microbial protein synthesis during non-eating periods ${ }^{29}$, and the impact that it may have on total microbial biomass production in the rumen and the consequent intestinal supply of microbial protein $^{30}$.

Another aspect of rumen function highlighted from the current results is that nutrient deprivation may expose the fundamental metabolic pathways of specific microbes. Identifying the proteins in HIGH0 may give insight into pathways that specific microbes deem vital. As highlighted by ${ }^{31}$, identifying and exploiting the roles of independent microbes or groups of microbes is a current challenge. The inclusion of proteomics in study methodology can more broadly highlight pathways affected by a treatment or physiologic state rather than focusing on a small set of parameters to directly or indirectly assess ruminal changes and can identify metabolic shifts that do not result in a change in microbial diversity. The use of dietary models in combination with these proteomic techniques is also proposed to be a feasible method to better identify the basic roles of the rumen microbes, and what protein-mediated pathways the different microbes divert to in different nutrient scenarios or feed management protocols.

This research is the first published work to report the rumen metaproteome beyond static points in time and demonstrates how proteomic technology can provide a meaningful contribution to the characterization of microbial activity and protein-mediated pathway dynamics. The trial reported herein demonstrates that the rumen protein profile is dynamic and appears to be sensitive to lower nutrient availability. Furthermore, this research supports the hypothesis that inclusion of proteomic technology to characterize the rumen metaproteome and the impact of diet, health, and environment on rumen functionality can provide a useful contribution and further advance our research to maximize production efficiency.

\section{Methods}

Animals and maintenance. Samples were collected from three lactating Holstein dairy cows $(207 \pm 53.5$ days in milk) housed at the Paul R. Miller Research Complex (The University of Vermont, Burlington, VT, USA). Cows were fed a nutritionally balanced dietary ration (diet chemical composition listed in Supplementary Table S3) ad libitum and were offered a total mixed ration twice daily (0630 h and $1430 \mathrm{~h}$ ) and a diet supplement (high grain pellet) four times daily $(0645 \mathrm{~h}, 1045 \mathrm{~h}, 1730 \mathrm{~h}$, and $2300 \mathrm{~h})$. All feed refusals were discarded prior to morning $(0630 \mathrm{~h})$ feeding daily. Cows had ad libitum access to water. Animal use and samplings methods performed in this trial were reviewed and approved by the Institutional Animal Care and Use Committee of the University of Vermont (Protocol \#16-029) in accordance with the requirements of the Office of Laboratory Animal Welfare.

Rumen sampling. As per sampling protocols previously described ${ }^{32-35}$, rumen fluid (RF) samples were collected from cows at $0630 \mathrm{~h}(0 \mathrm{~h}), 1030 \mathrm{~h}(4 \mathrm{~h})$, and $1230 \mathrm{~h}(6 \mathrm{~h})$ on day 1,3 , and 5 of a 5 -day protocol. The $0 \mathrm{~h}$ samples were collected after morning refusals were collected but immediately prior to initial TMR offerings.

As per methods outlined by Steele et al.$^{35}$, digesta grab samples were collected at each timepoint via a rumen cannula from beneath the fiber mat within the ventral sac of the rumen. A minimum of three digesta grab samples were collected per cow at each sampling point for a single representative sample per timepoint. Samples were immediately snap frozen in a dry-ice ethanol bath, transported on dry ice to the laboratory, and stored at $-80^{\circ} \mathrm{C}$ until processing.

Rumen sample processing. For processing, RF samples were thawed overnight at $4{ }^{\circ} \mathrm{C}$. Once thawed, samples were filtered through 4 layers of cheesecloth (Lion Services Inc., Charlotte, NC, USA), and filtered samples were composited within cow within timepoint across day for a representative sample of $0 \mathrm{~h}, 4 \mathrm{~h}$, and $6 \mathrm{~h}$ for each cow prior to freezing at $-80^{\circ} \mathrm{C}$. For centrifugation, the composited filtered samples were thawed on ice and centrifuged at $16,000 \times g$ for 20 minutes at $4^{\circ} \mathrm{C}$. The resulting supernatant was discarded, and the remaining pellets were retained.

The collected pellets were lysed using both chemical and mechanical lysis methods based on both Snelling and Wallace ${ }^{27}$ and Yu and Morrison ${ }^{36}$ with modifications. Briefly, $1.5 \mathrm{~mL}$ of RIPA lysis buffer containing protease inhibitor (Pierce ${ }^{\mathrm{TM}}$ Protease Inhibitor Mini Tablets, Thermo Scientific, Rockford, IL, USA) and a $5 \mathrm{~mm}$ stainless steel bead (Qiagen, Hilden, Germany) was added to each pelleted sample and samples were homogenized (TissueLyser II, Qiagen, Hilden, Germany) through six repetitions of lysis at $30 \mathrm{~Hz}$ for 30 seconds with a 3-min incubation on ice between each repetition, similar to the BeadBeater protocol reported by Luccitt et al. ${ }^{37}$. A subsample of each sample homogenate was pipetted into a clean tube and precipitated overnight at $4{ }^{\circ} \mathrm{C}$ in a lysis solution (6M TCA, $80 \mathrm{mM}$ DTT) (3:1 protein extract to TCA/DTT) similar to the protocol outlined by Snelling \& Wallace ${ }^{27}$.

Following the overnight incubation, the samples were vortexed and centrifuged at $16,000 \times g$ for 20 minutes at $4{ }^{\circ} \mathrm{C}$ and supernatants were discarded. The retained pellets were then washed four times as per methods of Snelling and Wallace ${ }^{27}$ with modifications by Song et al. ${ }^{38}$, where the retained pellets were washed in ice-cold $20 \%$ DMSO in acetone, incubated for 1 hour at $-20^{\circ} \mathrm{C}$, and centrifuged at $10,000 \times g$ for 5 minutes at $4{ }^{\circ} \mathrm{C}$. The supernatants were then discarded, and the pellets were again washed using the same protocol. This wash protocol was then repeated twice more using $100 \%$ ice-cold acetone. After the final wash, the collected pellets were air dried 
and resuspended in phosphate buffered saline. A new $5 \mathrm{~mm}$ stainless steel ball was added to each sample before samples were homogenized in the TissueLyser for 30 seconds at $30 \mathrm{~Hz}$. A universal control (UC) sample was generated by combining equal volumes from each of the 9 samples. Samples were stored at $-80{ }^{\circ} \mathrm{C}$ until protein quantification of samples was performed using the bicinchonic acid assay (BCA) kit (Pierce, Rockford, IL, USA).

TMT isobaric labeling, high $\mathrm{pH}$ reversed-phase peptide fractionation and liquid chromatographytandem mass spectrometry (LC-MS/MS). Quantified samples $(85 \mu \mathrm{g})$ were then labeled using TMT Isobaric Tags as per manufacturer instructions (Thermo Scientific, Rockford, IL, USA). Labeling efficiency of each samples was verified to be more than $96 \%$ through preliminary MS analysis of individual samples. Equal volumes $(75 \mu \mathrm{L})$ of each TMT-labeled sample was combined into a new tube and a $100 \mu \mathrm{L}$ aliquot was vacuum dried to remove the triethyl ammonium bicarbonate (TEAB). The peptides were then fractionated using the high $\mathrm{pH}$ reversed-phase peptide fractionation kit (Thermo Scientific, Rockford, IL, USA) as per kit instructions resulting in 8 fractions for LC-MS/MS per original sample. One-tenth of each of the fractionated samples was dried down and resuspended in $2.5 \%$ formic acid (FA) in water and $2.5 \%$ acetonitrile $\left(\mathrm{CH}_{3} \mathrm{CN}\right)$. The LC-MS/MS analysis was carried out on the Q-Exactive Plus mass spectrometer coupled to an EASY-nLC 1200 (Thermo Scientific, Waltham, MA, USA) performed by the VGN Proteomics Facility (Burlington, VT, USA). Peptides were separated using a gradient of $2.5-35 \% \mathrm{CH}_{3} \mathrm{CN} / 0.1 \% \mathrm{FA}$ over $60 \mathrm{~min}, 35-100 \% \mathrm{CH}_{3} \mathrm{CN} / 0.1 \% \mathrm{FA}$ in $1 \mathrm{~min}$ and then $100 \% \mathrm{CH}_{3} \mathrm{CN} / 0.1 \% \mathrm{FA}$ for $4 \mathrm{~min}$, followed by an immediate return to $2.5 \% \mathrm{CH}_{3} \mathrm{CN} / 0.1 \% \mathrm{FA}$ and a hold at $2.5 \%$ $\mathrm{CH}_{3} \mathrm{CN} / 0.1 \% \mathrm{FA}$. The nanospray and data acquisition methods were completed per Scuderi et al. ${ }^{39}$. Briefly, samples were loaded onto a $100 \mu \mathrm{m} \times 500 \mathrm{~mm}$ capillary column packed with Halo C18 $(2.7 \mu \mathrm{m}$ particle size, $90 \mathrm{~nm}$ pore size, Michrom Bioresources, CA, USA) at a flow rate of $300 \mathrm{~nL} \mathrm{~min}^{-1}$. The column end was laser pulled to a $\sim 3 \mu \mathrm{m}$ orifice and packed with minimal amounts of $5 \mathrm{um}$ Magic C18AQ before packing with the $3-\mu \mathrm{m}$ particle size chromatographic materials. Peptides were introduced into the mass spectrometer via a nanospray ionization source with a spray voltage of $2.0 \mathrm{kV}$. Mass spectrometry data was acquired in a data-dependent "Top 10" acquisition mode with lock mass function activated $(\mathrm{m} / \mathrm{z}$ 371.1012; use lock masses: best; lock mass injection: full MS), in which a survey scan from $\mathrm{m} / \mathrm{z} 350-1600$ at 70,000 resolution (AGC target $1 \mathrm{e}^{6}$; max IT $100 \mathrm{~ms}$; profile mode) was followed by 10 higher-energy collisional dissociation (HCD) tandem mass spectrometry (MS/MS) scans on the most abundant ions at 35,000 resolution (AGC target $1 \mathrm{e}^{5}$; max IT $100 \mathrm{~ms}$; profile mode). MS/MS scans were acquired with an isolation width of $1.2 \mathrm{~m} / z$ and a normalized collisional energy of $35 \%$. Dynamic exclusion was enabled (peptide match: preferred; exclude isotopes: on; underfill ratio: $1 \%$ ).

Data and statistical analysis. Product ion spectra were searched using SEQUEST and Mascot through Proteome Discoverer 2.2 (Thermo Scientific, Waltham, MA, USA) against 47 composite databases encompassing strains of 19 microbial species downloaded on Nov. 30, 2018, Jan. 29, 2019, and Nov. 11, 2019, including E. ruminantium (UP000189857), L. ruminis (UP000001279), T. bryantii (UP000182360), T. saccharophilum (UP000003571), F. succinogenes (UP000000517), M. barkeri 3 (UP000033066), M. elsdenii DSM20460 (UP000010111), O. formigenes HOxBLS (UP000003973), R. albus SY3 (UP000021369), R. flavefaciens 007c (UP000019365), W. succinogenes (UP000000422), B. hungatei MB2003 (UP000179284), B. hungatei XBD2006 (UP000183047), B. hungatei DSM 14810 (UP000184097), P. aff. ruminicola Tc2-24 (UP000199373), P. bryantii FB3001 (UP000182952), P. bryantii KHPX14 (UP000183264), P. bryantii TC1-1 (UP000216189), P. bryantii B14 (UP000004524; UP000183837), P. ruminicola (Bacteroides ruminicola) AR32 (UP000236735), P. ruminicola (Bacteroides ruminicola) ATCC 19189 (UP000183727), P. ruminicola (Bacteroides ruminicola) BPI-162 (UP000182287), P. ruminicola (Bacteroides ruminicola) BPI-34 (UP000184280), P. ruminicola (Bacteroides ruminicola) D31d (UP000182257), P. ruminicola (Bacteroides ruminicola) KHT3 (UP000184130), P. ruminicola ATCC 19189/JCM 8958/23 and ATCC 19189/JCM 8958/23 (UP000000927), P. cellulosolvens ATCC 35603/ DSM 2933 (UP000036923), P. ruminis ACV-9 (UP000182321), P. ruminis JK10 (UP000224317), P. ruminis JK626 (UP000225889), P. ruminis DSM 9787 (UP000219563), R. bromii strain 5AMG (UP000233562), R. bromii AF1536 (UP000283859), R. bromii AF21-10LB (UP000283293), R. bromii AF25-7LB (UP000286041), R. bromii AM3213AC (UP000284544), R. bromii AM46-2BH (UP000285083), R. bromii ATCC 27255 (UP000233425), R. bromii CF01-14 (UP000284438), R. bromii L2-36 (UP000233570), R. bromii TM09-18AC (UP000262420), R. bromii TM09-5AC (UP000264375), R. bromii TM10-21 (UP000263282), R. bromii YE282 (UP000198616), R. bromii L2-63 (UP000240927), and E. cellulosolvens (UP000005753). All 9 raw files were searched against the database as one contiguous input file. Search parameters were as follows: (1) full trypsin enzymatic activity; (2) mass tolerance at $10 \mathrm{ppm}$ and $0.02 \mathrm{Da}$ for precursor ions and fragment ions, respectively; (3) dynamic modifications: oxidation on methionine $(+15.995 \mathrm{Da})$; (4) dynamic TMT6plex modification on N-termini and lysine $(+229.163 \mathrm{Da})$; and (5) static carbamidomethylation modification on cysteines (+57.021 Da). Percolator node was included in the workflow to limit the false positive (FP) rates to less than $1 \%$ in the data set. The relative abundances of TMT labeled peptides were quantified with the Reporter Ions Quantifier node in the Consensus workflow and parameters were set as follows: (1) both unique and razor peptides were used for quantification; (2) Reject Quan Results with Missing Channels: False; (3) Apply Quan Value Corrections: False; (4) Co-Isolation Threshold: 50; (5) Average Reporter S/N Threshold=10; (6) "Total Peptide Amount" was used for normalization and (7) Scaling Mode was set "on Control Average", so that the peptide abundances in the UC labels were set as 100 and the abundances in other channels were scaled accordingly. Non-normalized data is listed in Supplementary Table S4. The normalized scaled abundance values were used for subsequent statistical analyses. For any proteins identified that remained "uncharacterized", either PANTHER Classification System ${ }^{40}$ was used to identify to protein name using the accession number, or the FASTA sequence was retrieved from UnitProt ${ }^{41}$ and searched through BLAST ${ }^{42}$ and the top hit protein was selected as the protein ID if above 99.0\% matched identity. PROC IML in SAS was used to determine appropriate weighting for orthogonal contrasts to determine linear and quadratic effects of time. 
The PROC MIXED of SAS was then utilized to determine the effect of time on the dependent variable of protein. Effect of time of sampling was deemed significant if $\mathrm{P}<0.050$.

Received: 21 June 2019; Accepted: 6 February 2020;

Published online: 21 February 2020

\section{References}

1. Jami, E., White, B. A. \& Mizrahi, I. Potential role of the bovine rumen microbiome in modulating milk composition and feed efficiency. PLoS One 9(1), e85423, https://doi.org/10.1371/journal.pone.0085423 (2014).

2. Jewell, K. A., McCormick, C. A., Odt, C. L., Weimer, P. J. \& Suen, G. Ruminal bacterial community composition in dairy cows is dynamic over the course of two lactations and correlates with feed efficiency. Appl. Environ. Microbiol. 81(14), 4697-4710, https:// doi.org/10.1128/AEM.00720-15 (2015).

3. Li, X. Z. et al. Effects of dietary linseed oil and propionate precursors on ruminal microbial community, composition, and diversity in Yanbian yellow cattle. PLoS one 10(5), e0126473, https://doi.org/10.1371/journal.pone.0126473 (2015).

4. Shabat, S. K. B. et al. Specific microbiome-dependent mechanisms underlie the energy harvest efficiency of ruminants. ISME J. 10(12), 2958, https://doi.org/10.1038/ismej.2016.62 (2016).

5. Weimer, P. J., Stevenson, D. M., Mantovani, H. C. \& Man, S. L. C. Host specificity of the ruminal bacterial community in the dairy cow following near-total exchange of ruminal contents. J. Dairy. Sci. 93(12), 5902-5912, https://doi.org/10.3168/jds.2010-3500 (2010).

6. Bainbridge, M. L., Cersosimo, L. M., Wright, A. D. G. \& Kraft, J. Rumen bacterial communities shift across a lactation in Holstein, Jersey and Holstein $\times$ Jersey dairy cows and correlate to rumen function, bacterial fatty acid composition and production parameters. FEMS Microbiol. Ecol. 92(5), fiw059, https://doi.org/10.1093/femsec/fiw059 (2016).

7. Schären, M. et al. Interrelations between the rumen microbiota and production, behavioral, rumen fermentation, metabolic, and immunological attributes of dairy cows. J. Dairy. Sci. 101(5), 4615-4637, https://doi.org/10.3168/jds.2017-13736 (2018).

8. Belanche, A. et al. In vitro assessment of the factors that determine the activity of the rumen microbiota for further applications as inoculum. J. Sci. Food Agric. 99(1), 163-172, https://doi.org/10.1002/jsfa.9157 (2019).

9. Morvay, Y., Bannink, A., France, J., Kebreab, E. \& Dijkstra, J. Evaluation of models to predict the stoichiometry of volatile fatty acid profiles in rumen fluid of lactating Holstein cows. J. Dairy. Sci. 94(6), 3063-3080, https://doi.org/10.3168/jds.2010-3995 (2011).

10. Niu, M. et al. Prediction of enteric methane production, yield, and intensity in dairy cattle using an intercontinental database. Glob. Change Biol. 24(8), 3368-3389, https://doi.org/10.1111/gcb.14094 (2018).

11. Wang, X. et al. Correlation between composition of the bacterial community and concentration of volatile fatty acids in the rumen during the transition period and ketosis in dairy cows. Appl. Environ. Microbiol. 78(7), 2386-2392, https://doi.org/10.1128/ AEM.07545-11 (2012).

12. Comtet-Marre, S. et al. FibroChip, a functional DNA microarray to monitor cellulolytic and hemicellulolytic activities of rumen microbiota. Front. Microbiol. 9, 215, https://doi.org/10.3389/fmicb.2018.00215 (2018).

13. Palmonari, A., Stevenson, D. M., Mertens, D. R., Cruywagen, C. W. \& Weimer, P. J. pH dynamics and bacterial community composition in the rumen of lactating dairy cows. J. Dairy. Sci. 93(1), 279-287 (2010).

14. Söllinger, A. et al. Holistic Assessment of Rumen Microbiome Dynamics through Quantitative Metatranscriptomics Reveals Multifunctional Redundancy during Key Steps of Anaerobic Feed Degradation. MSystems. 3(4), e00038-18, https://doi.org/10.1128/ mSystems.00038-18 (2018).

15. Hart, E. H., Creevey, C. J., Hitch, T. \& Kingston-Smith, A. H. Meta-proteomics of rumen microbiota indicates niche compartmentalisation and functional dominance in a limited number of metabolic pathways between abundant bacteria. Sci. Rep. 8(1), 10504, https://doi.org/10.1038/s41598-018-28827-7 (2018).

16. Chen, L. et al. Megasphaera elsdenii Lactate Degradation Pattern Shifts in Rumen Acidosis Models. Front. Microbiol. 10, 162, https:// doi.org/10.3389/fmicb.2019.00162 (2019).

17. Reinhardt, T. A., Sacco, R. E., Nonnecke, B. J. \& Lippolis, J. D. Bovine milk proteome: quantitative changes in normal milk exosomes, milk fat globule membranes and whey proteomes resulting from Staphylococcus aureus mastitis. J. Proteomics. 82, 141-154, https:// doi.org/10.1016/j.jprot.2013.02.013 (2013).

18. Tacoma, R., Fields, J., Ebenstein, D. B., Lam, Y. W. \& Greenwood, S. L. Characterization of the bovine milk proteome in earlylactation Holstein and Jersey breeds of dairy cows. J. Proteomics. 130, 200-210, https://doi.org/10.1016/j.jprot.2015.09.024 (2016).

19. Yang, Y. et al. Proteomic analysis of cow, yak, buffalo, goat and camel milk whey proteins: quantitative differential expression patterns. J. Proteome Res. 12(4), 1660-1667, https://doi.org/10.1021/pr301001m (2013).

20. Bathla, S. et al. Profiling of urinary proteins in Karan Fries cows reveals more than 1550. proteins. J. Proteomics. 127, 193-201, https://doi.org/10.1016/j.jprot.2015.05.026(2015).

21. Rawat, P. et al. Identification of potential protein biomarkers for early detection of pregnancy in cow urine using $2 \mathrm{D}$ DIGE and label free quantitation. Clin. Proteomics. 13(1), 15, https://doi.org/10.1186/s12014-016-9116-y (2016).

22. Xu, C. et al. Mass spectral analysis of urine proteomic profiles of dairy cows suffering from clinical ketosis. Vet. Q. 35(3), 133-141, https://doi.org/10.1080/01652176.2015.1055352 (2015).

23. Kinkead, R. A., Elliott, C. T., Cannizzo, F. T., Biolatti, B. \& Mooney, M. H. Proteomic identification of plasma proteins as markers of growth promoter abuse in cattle. Anal. Bioanal. Chem. 407(15), 4495-4507, https://doi.org/10.1007/s00216-015-8651-0 (2015).

24. Sun, D., Zhang, H., Guo, D., Sun, A. \& Wang, H. Shotgun proteomic analysis of plasma from dairy cattle suffering from footrot: characterization of potential disease-associated factors. PLoS One 8(2), e55973, https://doi.org/10.1371/journal.pone.0055973 (2013).

25. Forde, N. et al. Proteomic analysis of uterine fluid during the pre-implantation period of pregnancy in cattle. Reproduction. 147(5), 575-587, https://doi.org/10.1530/REP-13-0010 (2014).

26. Zachut, M., Sood, P., Levin, Y. \& Moallem, U. Proteomic analysis of preovulatory follicular fluid reveals differentially abundant proteins in less fertile dairy cows. J. Proteomics. 139, 122-129, https://doi.org/10.1016/j.jprot.2016.03.027 (2016).

27. Snelling, T. J. \& Wallace, R. J. The rumen microbial metaproteome as revealed by SDS-PAGE. BMC Microbiol. 17, 9, https://doi. org/10.1186/s12866-016-0917-y (2017).

28. Russell, J. Rumen microbiology and its role in ruminant nutrition. Ithaca, N.Y.: James B. Russell, p.17. (2002).

29. Martineau, R. et al. Relation of net portal flux of nitrogen compounds with dietary characteristics in ruminants: A meta-analysis approach. J. Dairy. Sci. 94(6), 2986-3001, https://doi.org/10.3168/jds.2010-3438 (2011).

30. Schwab, C. G. \& Broderick, G. A. A 100-Year Review: Protein and amino acid nutrition in dairy cows. J. Dairy. Sci. 100(12), 10094-10112, https://doi.org/10.3168/jds.2017-13320 (2017).

31. Weimer, P. J. Redundancy, resilience, and host specificity of the ruminal microbiota: implications for engineering improved ruminal fermentations. Front. microbiol. 6, 296, https://doi.org/10.3389/fmicb.2015.00296 (2015).

32. Hook, S. E., Steele, M. A., Northwood, K. S., Wright, A. D. G. \& McBride, B. W. Impact of high-concentrate feeding and low ruminal $\mathrm{pH}$ on methanogens and protozoa in the rumen of dairy cows. Microb. Ecol. 62(1), 94-105, https://doi.org/10.1007/s00248-0119881-0 (2011). 
33. Khafipour, E., Plaizier, J. C., Aikman, P. C. \& Krause, D. O. Population structure of rumen Escherichia coli associated with subacute ruminal acidosis (SARA) in dairy cattle. J. Dairy. Sci. 94(1), 351-360, https://doi.org/10.3168/jds.2010-3435 (2011).

34. Latham, E. A., Weldon, K. K., Wickersham, T. A., Coverdale, J. A. \& Pinchak, W. E. Responses in the rumen microbiome of Bos taurus and indicus steers fed a low-quality rice straw diet and supplemented protein. J. Anim. Sci. 96(3), 1032-1044, https://doi. org/10.1093/jas/sky023 (2018).

35. Steele, M. A., Dionissopoulos, L., AlZahal, O., Doelman, J. \& McBride, B. W. Rumen epithelial adaptation to ruminal acidosis in lactating cattle involves the coordinated expression of insulin-like growth factor-binding proteins and a cholesterolgenic enzyme. $J$. Dairy. Sci. 95, 318-327, https://doi.org/10.3168/jds.2011-4465 (2012).

36. Yu, Z. \& Morrison, M. Improved extraction of PCR-quality community DNA from digesta and fecal samples. Biotechniques. 36, 808-812, https://doi.org/10.2144/04365ST04 (2004).

37. Lucitt, M. B. et al. Analysis of the Zebrafish Proteome during Embryonic Development. Mol. Cell Proteomics. 7, 981-994, https://doi. org/10.1074/mcp.M700382-MCP200 (2008).

38. Song, Y., Zhang, H., Wang, G. \& Shen, Z. DMSO, an organic cleanup solvent for TCA/acetone-precipitated proteins, improves 2-DE protein analysis of rice roots. Plant. Mol. Biol. Repor. 30, 1204-1209, https://doi.org/10.1007/s11105-012-0442-6 (2012).

39. Scuderi, R. A., Ebenstein, D. B., Lam, Y. W., Kraft, J. \& Greenwood, S. L. Inclusion of grape marc in dairy cattle rations alters the bovine milk proteome. J. Dairy. Res. 86, 154-161, https://doi.org/10.1017/S0022029919000372 (2019).

40. Mi, H., et al Protocol Update for large-scale genome and gene function analysis with the PANTHER classification system (v. 14.0). Nature protocols. 1 (2019).

41. Chen, C., Huang, H. \& Wu, C. H. Protein Bioinformatics Databases and Resources. Methods. Mol. Biol. 1558, 3-39, https://doi. org/10.1007/978-1-4939-6783-4_(2017).

42. Camacho, C. et al. BLAST+: architecture and applications. BMC Bioinformatics. 10, 421 (2008).

\section{Acknowledgements}

The authors would like to thank The University of Vermont Genetics Network (Burlington, VT, USA), specifically Dr. Ying Wai Lam for aiding in development of the fractionation protocol and for LC-MS/MS operation and database search completion. The authors also thank students of the Summer 2018 Cooperative for Real Education in Agricultural Management (CREAM) and staff at the Paul R. Miller Research Facility (University of Vermont, Burlington, VT, USA) for assisting when needed during milk sampling. This research was funded by USDA HATCH VT-H02310 and an Institutional Development Award (IdeA) from the National Institute of General Medical Sciences of the National Institutes of Health Grant number P20GM103449.

\section{Author contributions}

M.C.H. completed trial work and laboratory processing, analyzed data, and manuscript preparation. S.L.G. participated in oversight of study design, statistical analysis, and manuscript development.

\section{Competing interests}

The authors declare no competing interests.

\section{Additional information}

Supplementary information is available for this paper at https://doi.org/10.1038/s41598-020-59974-5.

Correspondence and requests for materials should be addressed to S.L.G.

Reprints and permissions information is available at www.nature.com/reprints.

Publisher's note Springer Nature remains neutral with regard to jurisdictional claims in published maps and institutional affiliations.

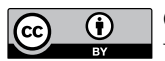

Open Access This article is licensed under a Creative Commons Attribution 4.0 International License, which permits use, sharing, adaptation, distribution and reproduction in any medium or format, as long as you give appropriate credit to the original author(s) and the source, provide a link to the Creative Commons license, and indicate if changes were made. The images or other third party material in this article are included in the article's Creative Commons license, unless indicated otherwise in a credit line to the material. If material is not included in the article's Creative Commons license and your intended use is not permitted by statutory regulation or exceeds the permitted use, you will need to obtain permission directly from the copyright holder. To view a copy of this license, visit http://creativecommons.org/licenses/by/4.0/.

(C) The Author(s) 2020 